\section{Around About}

\section{Science Spending Down}

Sciences programmes fared fairly well in the US 1996 budget which has finally been agreed by Congress and the President. Nonmilitary science and technology spending will be $3 \%$ less than for fiscal 1995 ( $5 \%$ with inflation) as compared with a $9 \%$ cut for the total non-military budget.

The UK's Science and Technology Office reports in its annual Forward Look that government spending on research and technology decreased by $26 \%$ in real terms in the period 1985-95. Most of the decline has come from reductions in spending for defence and by government departments, in line with the government's commitment to make industry responsible for investment in these areas. Univer-

\section{Dutch Physics Festival}

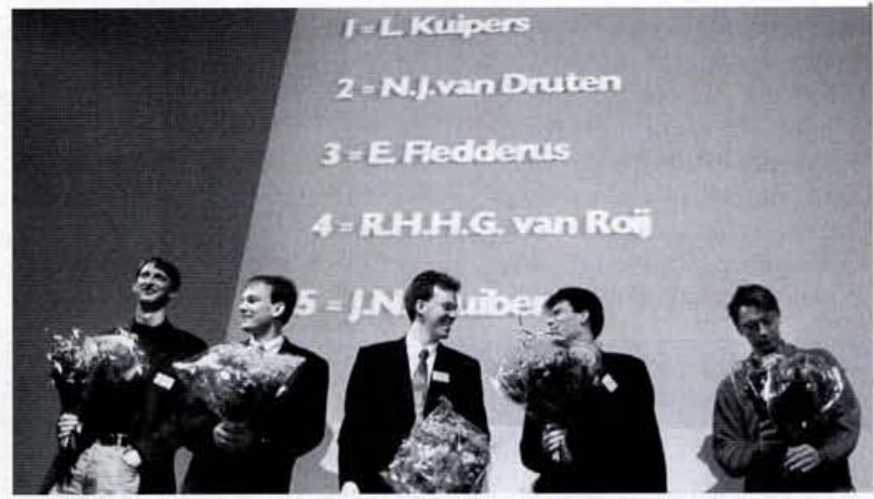

The Jaarbeurs Congress Centre in Utrecht saw over a thousand physicists and other physics' enthusiasts come together on 11 April to celebrate the 75th anniversary of The Netherlands Physical Society and the 5oth anniversary of the Dutch physics research council FOM. The crowd was treated on an exhibition on the current state of physics in Holland, a session on physics and science policy, a special talk by good old Nico van Kampen, a concert by an orchestra of about 50 physicists, drinks, etc.

A highlight of the day was the final of a young physicists' lecture competition, which started off in January with 31 candidates. The competition's five best speakers were invited sity and research council spending increased in the same period by $13 \%$, so its share of total government S\&T spending rose from $35 \%$ in 1985 to $55 \%$ in 1995 .

Germany's research minister has reported that federal funding for research as a percentage of GDP decreased in Germany from a plateau of $2.9 \%$ in $1987-91$ to $2.3 \%$ in 1995 . There has also been a considerable reduction in the proportion of domestic research financed by industry.

\section{UK Physics Labs Stay Public}

The UK government has announced following reviews of 12 out of 40 national labs employing 20000 that the Central Laboratory for the Research Councils (CLRC) formed in 1995 by merging the Daresbury and RutherfordAppleton laboratories will remain in the public sector. The CLRC, with 1900 staff and the UK's main the switchable yttrium the first author, was the cover story for the 21 March 1996 issue of Nature. [H. Eggen, Utrecht] provider of physics facilities, was deemed to be already running successfully along private-sector lines with most work coming from competitive tenders. The CLRC inaugurated Titania, the world's most powerful UV laser (10 TW/30o fs pulses), on 2 April. The facility will be used for plasma physics studies, aspects of inertial confinement fusion, $\mathrm{x}$-ray laser development, and the generation and application of extreme UV laser harmonics.

\section{ESTA Backs Science and ICF}

The European Union's European Science and Technology Assembly (ESTA) argues in a recent statement that every programme in the EU's next Framework should include a basic research component to fund "bottom-up" proposals (few have one at present and they are heavily oversubscribed). ESTA also says that the European Commission should develop "common scientific objectives" between national research councils and European research organizations.

Meanwhile, ESTA's 20member bureau is seeking a successor to the ESTA chairman Jan Borgman, whose resignation protesting ESTA's inadequate resources for its administrative workload involving several working groups is pending.

An ESTA draft report, and the first on a subject of its own choosing, has recommended that the percentage of EU fusion programme spending on inertial confinement fusion (ICF) should be increased from $1-2 \%$ to $10 \%$ by diverting funds from magnetic confinement fusion in order to develop an ICF programme comparable to those in the US and Japan. Meanwhile, the Joint European Torus has won final approval for a three-year extension until the end of 1999 to provide research in support of the thermonuclear fusion reactor ITER.

W 7-X Fusion Reactor Agreed

Agreements have been signed by the European Union's fusion programme, the German federal government and the state of Mecklenburg-Vorpommern for the construction of the $320 \mathrm{MDM}$ Wendelstein 7 -X stellarator fusion reactor at the Institute of Plasma Physics (IPP) Greifswald laboratory. Tenders for constructing the facility, with a planned staff of 300 , will now be sent out and completion by 2004 is planned.

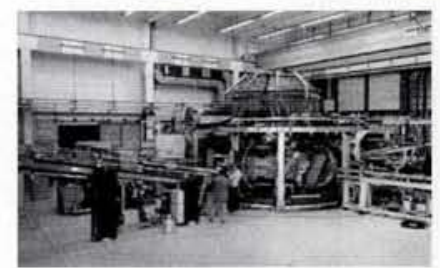

The IPP, Garching, Wendelstein 7-AS fusion stellarator. Construction of the next in the series, an optimised 7-X version, starts shortly at the IPP's Greifswald laboratory, the former East German Institute of Low-Temperature Plasma Physics.

Experiments in support of ITER mean that $45 \%$ of the investment comes from the EU, and the IPP hopes that there will be commitments in future Framework programmes to cover operating costs.

COBRAS/SAMBA Selected

The European Space Agency's (ESA) Space Science Advisory Committee has recommended COBRAS/SAMBA as the agency's third, approximately $350 \mathrm{MECU}$, Horizon programme mediumsized $\mathrm{M}_{3}$ mission. The proposed launch data of around 2004 is one year later than originally foreseen owing to the $3 \%$ p.a. reduction in ESA's science budget that was agreed to by ESA Member States last year. COBRAS/SAMBA will offer 10-times greater sensitivity and 50-times more angular resolution than the COBE spacecraft that discovered irregularities in the cosmic radiation background in 1992. The other most highly ranked mission was Intermarsnet to study Mars, but there were doubts that NASA's launch date of 2003 could be met and an Ariane 5 launch was too expensive. The committee recommended that the ESA Executive consider the lunar orbiter MORO in the framework of ESA's lunar initiative, which was recommended by the last meeting of ESA ministers. Modest support should be given to a simplified version of STEP (low-cost missions to test the equivalence principle have been proposed by the French CNES space agency and by NASA). Finally, a less ambitious stellar seismology mission of the type being considered by some Member States should come before the proposed STARS mission to probe the internal structures of a wide range of stars. mirror, which with Huiberts as

\section{Neutrons for the US}

Following the US Department of Energy (DoE) decision last year to cancel the $3000 \mathrm{M} \$ \mathrm{US}$ 